\section{MEDICINE AND THE NAVY Vol. II, I649-1714}

By J. J. KeEvil, M.D. Pp. 332, illustrated. Edinburgh: E. \& S. Livingstone Ltd. 1948. 40 s.

It is sad to realize that since the first volume of this important work was published its distinguished author has been taken from us. In his tribute to Surgeon-Commander Keevil, as a man of action and letters, and in this a man after his own heart, Sir Gordon Gordon-Taylor tells us much that we should know about the author to appreciate further the work which follows. This second volume bears the same mark of thoroughness and accuracy as the first, and as the Royal Navy reaches new phases of greatness in its pages, so the medical historian finds growing treasure in the reading of them. Pepys and Admiralty, ships, scurvy and sea fights, the beginnings of a medical conscience stirring where authority rested, all these things are framed in the everyday matters of the times, the slop-chit as it were, the key to the past. It is a book to live with and to take down again and again for its human interest as well as for reference.

\section{H.H.G.E.}

\section{RECENT ADVANCES IN OTO- LARYNGOLOGY}

By F. BOyes Korkis, M.B., F.R.C.S., D.L.O. Pp. ix +438 , fully illustrated. London: J. \& A. Churchill Ltd. 1958. 60s.

In the last five years, advances of impressive magnitude have been achieved in the field of otolaryngology. The author, by his industry, has achieved his purpose of a broad and comprehensive survey of the progress made.

It is of importance to note that the modern pathological basis of disease in the speciality has been emphasized wherever possible. In fact, be it on a pathological or physiological basis or in a plea for a standard clinical classification of laryngeal carcinoma, there is evidence of rationality which commands attention.

There is, nonetheless, some comment of a controversial nature, for example, the treatment of pharyngeal diverticulum or the treatment of laryngeal carcinoma in special centres with which some will disagree. More detail might have been desirable in the section on tympanoplasty. These are comments in the particular and do not weight heavily in the final assessment.

\section{GRAY'S ANATOMY}

Edited by T. B. Johnston, C.B.E., M.D., D. V. Davies, M.A. (Cantab.), M.B., B.S., and F. Davies, M.D., D.Sc. (Lond.), F.R.C.S. Thirtysecond (Centenary) Edition. Pp. xxiii + r,604. London: Longmans, Green \& Co. 1958. 126s.

With this edition Gray's Anatomy completes one hundred years of continuous publication. This is a remarkable achievement and is a tribute not only to the original author of the book and its successive editors, but to its popularity as well.

In the present edition no attempt has been made to alter the general character of the work, nor to shift the main emphasis away from the minute detailing of macroscopic human anatomy. While other aspects such as radiological and functional anatomy, growth and post-natal development, histochemistry, and the broader biological overtones of the subject receive some mention, the relative amount of space allotted to them is small and hardly reflects the importance attached to them in current anatomical teaching. The main differences between this and the previous edition lie in a certain amount of rewriting and revision of the sections on histology and embryology, in the inclusion of a number of excellent electron micrographs, and in the fuller treatment now given to the structure of vascular tissues, nerve endings, and the cerebral cortex. In the various sections dealing with the gross anatomy of the body, changes have also been made here and there to bring the account up to date. In these respects the present edition is a considerable improvement on the previous one.

Not so very long ago Gray, or a textbook of similar size and character, formed the main basis of undergraduate reading in anatomy. At that time, much emphasis was laid upon the detailed minutiae of gross structure and comparatively little upon other aspects of the subject such as those mentioned above. Nowadays, however, a considerably less intimate knowledge of detail is required of the student and in consequence much of the book is likely to remain unread by him, and he will probably find the sections on histology and 